\title{
OP38
}

\section{TOWARD COLOUR RENDERING METHOD OF WINDOW GLASS}

\author{
Barbara Matusiak et al.
}

DOI 10.25039/x46.2019.OP38

from

CIE x046:2019

\section{Proceedings}

of the

29th CIE SESSION

Washington D.C., USA, June 14 - 22, 2019

(DOI 10.25039/x46.2019)

The paper has been presented at the 29th CIE Session, Washington D.C., USA, June 14-22, 2019. It has not been peer-reviewed by CIE.

(C) CIE 2019

All rights reserved. Unless otherwise specified, no part of this publication may be reproduced or utilized in any form or by any means, electronic or mechanical, including photocopying and microfilm, without permission in writing from CIE Central Bureau at the address below. Any mention of organizations or products does not imply endorsement by the CIE.

This paper is made available open access for individual use. However, in all other cases all rights are reserved unless explicit permission is sought from and given by the CIE.

CIE Central Bureau

Babenbergerstrasse 9

A-1010 Vienna

Austria

Tel.: +4317143187

e-mail: ciecb@cie.co.at

www.cie.co.at 


\title{
TOWARD COLOUR RENDERING METHOD OF WINDOW GLASS
}

\author{
Barbara Szybinska Matusiak ${ }^{1}$, Shabnam Arbab ${ }^{2}$ \\ 1,2 Norwegian University of Science and Technology, Trondheim, NORWAY
}

Barbara.matusiak@ntnu.no

DOI $10.25039 / \times 46.2019 .0 P 38$

\begin{abstract}
The objective was to develop colour rendering method for window glass, including high-tech glazings. The study relates to the work of Joe Lynes, who proposed colour rendering of tinted glazing using the three colour dimensions: Value, Chroma and Hue. An experiment has been carried out in the Artificial Sky at NTNU (6500K). The colorimetric measurements of eight CIE colour samples illuminated by the light passing through different glazing types (and no-glass) were taken with the SpectraScan PR655. Expert observers evaluated colour shift (glass vs. noglass) in terms of Value, Chroma and Hue using Munsell Color Book. A good measure of perceived shift of Value is 1-Tmedian. The shift in Chroma may be predicted roughly by the square root of the quotient of gamut areas of glazing and no-glazing. The average shift distance at the u'v' diagram, multiplied by 100 , gives a good prediction of Hue shift expressed in Munsell points.
\end{abstract}

Keywords: Colour Rendering, Window Glass, Calorimetry, CIE u'v', Munsell Color System

\section{Introduction}

The CIE Colour Rendering Index (CRI), defined in CIE 13.3-1995, especially the general colour rendering index $R_{a}$, is widely used by the lighting industry both, in standards and in the lighting design practice. However, limitations of the CRI, especially for solid-state light sources, generated the need for developing of a measure that is more precise, namely colour fidelity index $R_{f}$ (Yaguchi et al., 2017). Still, the $R_{f}$, as well as $R_{a}$ does not address perception related colour quality measures, beyond overall fidelity, in a clear and simple way. The main difference between the $R_{a}$ and $R_{f}$ is precision, while calculation of $R_{a}$ is based on 8 samples, 99 samples need to be used for $R_{\mathrm{f}}$.

For architects and interior architects working with coloration of surfaces the question addressing the way light influence colour appearance is much broader. In addition to the general information about the change, it is important to know if the surface colour appears as lighter or darker Value, more or less coloured Chroma, and if it is possible to observe changes in Hue. Just, the usage of those three colour dimensions is necessary to describe the colour change in a way useful for (interior) architects. This can be done with the help of colour systems.

The two most known (and used by architects) colour systems nowadays, the NCS colour system and the Munsell color system, both are created with the vertical Value axis (white on the top and black in the bottom), and the Hue circle around. Chroma is defined as the distance from the Value axis. 


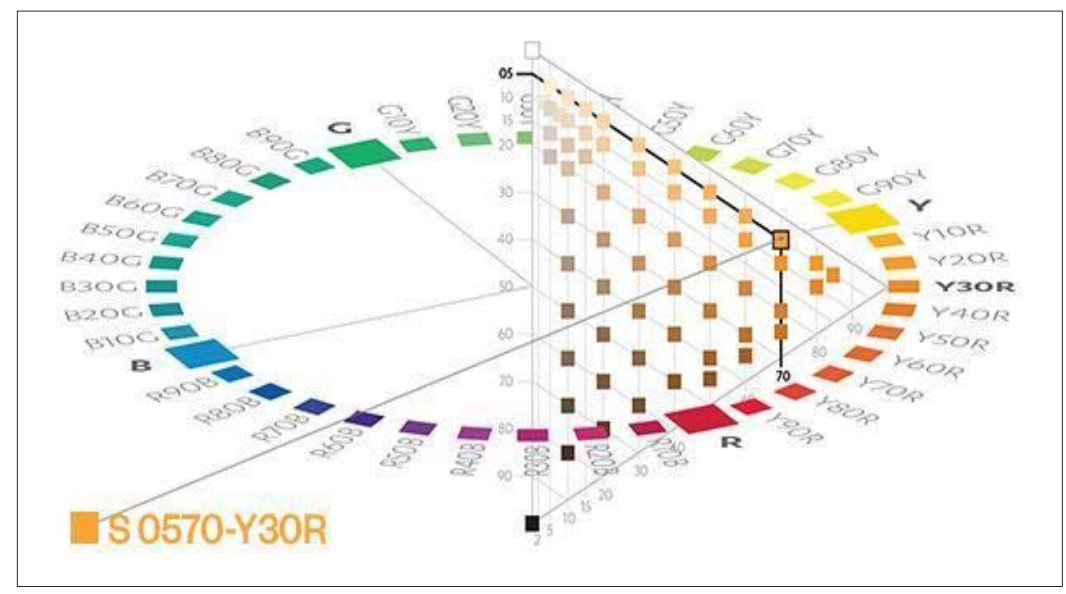

Figure 1 - NCS color system, collected from

https://www.asianpaints.com/colourquotient/showcase/the-natural-colour-system/

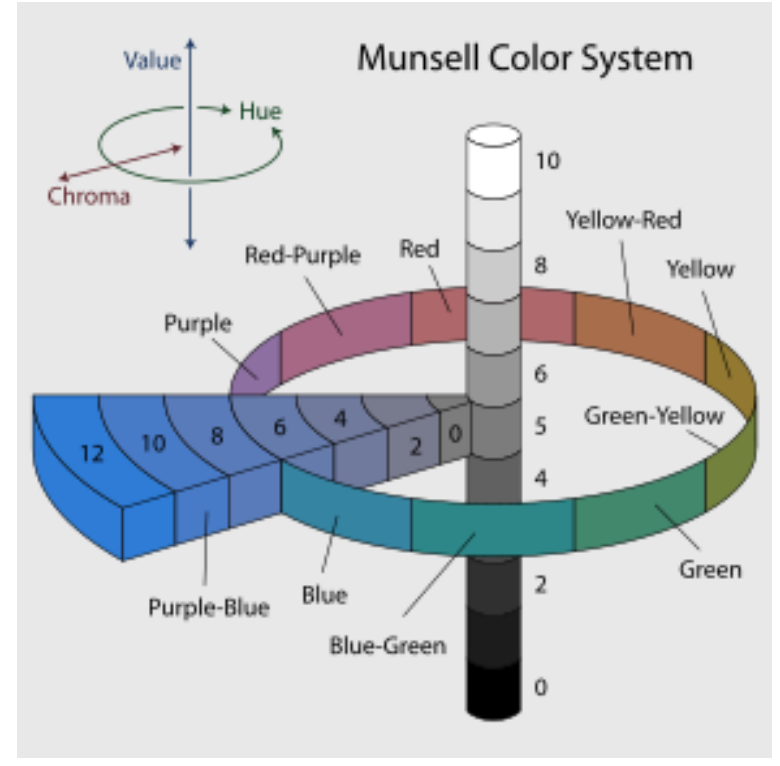

Figure 2 - Munsell color system, collected from the Wikipedia,

https://en.wikipedia.org/wiki/Munsell_color_system\#/media/File:Munsell-system.svg

The academic discussion about the colour rendering is mostly limited to electric light sources, but the present development in glass technology results in new types of glass having significant colour tint. The application of them in buildings is even more severe, as the live spam of windows is much longer than it is for lamps and the exchange of windows is much more expensive. Still, to the knowledge of the authors, the only scientist who proposed colour rendering of tinted glazing using the three colour dimensions (Value, Chroma and Hue) has been Joe Lynes (Lynes, 2015).

\subsection{Joe Lynes's approach}

\subsubsection{Gamut area}

According to Lynes, within reasonable limits and up to a certain point, people like to see surface colours strengthened. A large gamut area is preferred to small gamut area, gamut areas of different light sources are shown in Figure 3.

Gamut area is one of potential criterions for Chroma rendering of window glasses. However, following Lynes: the gamut area is a property of light sources, and window glass is not a light source, but a filter of a daylight source, so the gamut area for window glass depends also on the spectrum of the daylight source. 
It can be said that the rendering potential of window glass is the gamut area of its transmittance. Thus, calculating the gamut area for window glasses is applicable only if we assume the presence of a standard neutral (light) source (such as the artificial sky at the daylight laboratory at NTNU).

\subsubsection{Transmittance ratio}

According to Lynes, the ability of window glass to preserve surface reflectance is given by the transmittance ratio that is defined as min./max wavelength transmittance.

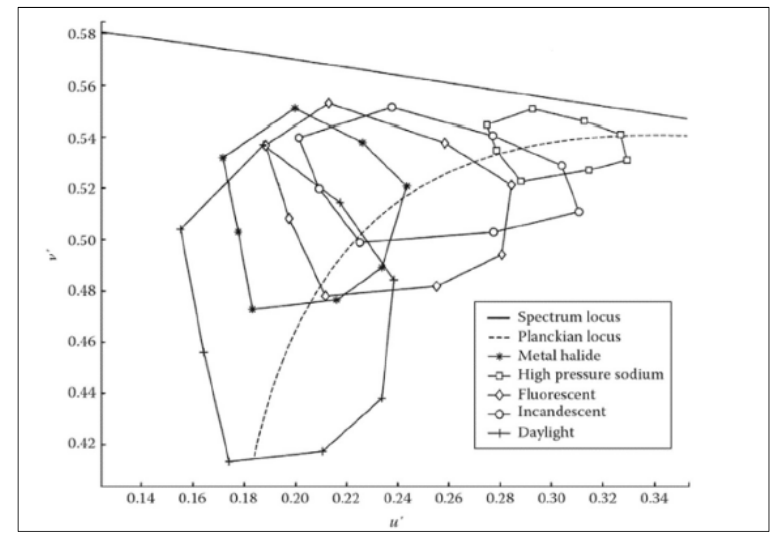

Figure 3 - Gamut area of different light sources, collected from Peter Boyce (2016).

\subsubsection{Hue conservation index}

As Lynes mentioned, one of the possible reasons that the window glass causes hue shift is a roller-coaster transmittance/reflectance curve.

"The nightmare scenario can occur when both the glass and surface have a roller coaster between 525 and $760 \mathrm{~nm}$ ". The roller coaster effect is a situation in which there are many big and sudden changes in the SPD line.

The Hue Conservation Index $(\mathrm{HCl})$ formula as proposed by Lynes is shown in equation 1:

Hue Conservation Index $\mathrm{HCl}=1-\frac{T c-T d}{T a+T b}$

Where:

$\begin{array}{ll}\text { Ta } & \text { Transmittance at } 525 \mathrm{~nm} \\ \text { Tb } & \text { Transmittance at } 700 \mathrm{~nm} \\ \text { TC } & \text { Transmittance at peak } \\ \text { Td } & \text { Transmittance at trough }\end{array}$

\subsection{Motivation}

Lynes developed his approach for slightly body-tinted glass; he did not consider glass types having unusual (for window glass) spectral transmittance e.g. having transmittance close to zero at a part of the spectrum. In such a case, the transmittance ratio as a measure of Value is problematic; not only min. wavelength transmittance but also the transmittance ratio will be zero resulting with zero Value for a glazing which actually transmit considerably amount of light. The previous study (Arbab et.al. 2017) was motivated by the following question:

Is the colour rendering method of glass proposed by Joe Lynes reliable also for present-day high-tech glazing types?

To find an answer an experiment has been carried out in the artificial sky at Norwegian University of Science and Technology's (NTNU) (Matusiak, 2014). This artificial sky simulator 
enables mimicking of skylight of the following correlated colour temperatures: $2700 \mathrm{~K}, 6500 \mathrm{~K}$ and $8000 \mathrm{~K}$. Three high-tech glazing types (electrochromic, photochromic and thermotropic) were used in five different transmittance scenarios (Arbab et.al. 2017). Colorimetric measurements were taken with the SpectraScan PR655 spectroradiometer.

The findings indicated that the Lynes method is reliable to predict which glazing has the biggest impact on all aspects of colour, but only to a limited degree for 6500K. (Arbab et al 2018)

One single number, as it is in the case of $R_{a}$ index for electric light, will never describe well enough HOW the various colours change. It is reasonable to refer to the three principal dimensions of colour: Value, Chroma and Hue.

The objective of the present study is to develop a new set of measures that together can be applied as Colour Rendering Method for Window Glass. With other words, the ambition is to predict the changes of Value, Chroma and Hue as observed by viewers on the basis of the colorimetric measurements of eight CIE colour samples.

The hypothesis was that the three colour dimensions can be addressed in the following way.

1. Value -the median spectral transmittance of the glass under examination.

2. Chroma -the gamut area on the v' u' graph (behind glass) in relation to the gamut area for no glass.

3. Hue, the average colour shift distance of the eight CIE colour samples (reference conditions vs. behind glass) on the v' u' graph.

\section{Experimental Method}

The experiment was designed such that the human observation of the colour shift due to glazing could be compared to the numerical colorimetric data.

Two light grey boxes having window-like openings on the side walls have been positioned at a table at the middle of the artificial sky (only the $6500 \mathrm{~K}$ was used in the present study) in the Daylight laboratory, see Figure 4 . The window in the right box (test box) was successively covered by different glass type samples, while the window in the left box (reference box) was kept uncovered for the reference. Two equal colour samples, representing one of the CIE colours shown in Table 1, were located on the boxes floor in equal distances from the window, see Figure 4. During the experiment observers could easily look into both boxes to compare the colour of the two samples. The vertical openings as well as the head of the observer were covered by a black, light-tight textile, such that the samples were illuminated only by the light coming through the windows. Depending on the glass type, the perceived colour of the sample (and the colour of the room) in the test box changed, as can be observed on the small photos to the right in Figure 4.

Table 1 - CIE colour samples used in the experiment

\begin{tabular}{|l|l|l|}
\hline & Name & Munsell Notation \\
\hline$\square$ & TCS01 & $7,5 \mathrm{R} 6 / 4$ \\
\cline { 2 - 3 } & TCS02 & $5 \mathrm{Y} 6 / 4$ \\
\cline { 2 - 3 } & TCS03 & $5 \mathrm{GY} 6 / 8$ \\
\cline { 2 - 3 } & TCS04 & $2,5 \mathrm{G} 6 / 6$ \\
\cline { 2 - 3 } & TCS05 & $10 \mathrm{BG} 6 / 4$ \\
\cline { 2 - 3 } & TCS06 & $5 \mathrm{~PB} 6 / 8$ \\
\cline { 2 - 3 } & TCS07 & $2,5 \mathrm{P} 6 / 8$ \\
\cline { 2 - 3 } & TCS08 & $10 \mathrm{P} \mathrm{6/8}$ \\
\hline
\end{tabular}

For each glass observers were asked if, and in the case how much, the Hue of the sample in the test box was different from the sample in the reference box. To collect as precise answers as possible, the subjects were given a Munsell circle, see Figure 5, made of small colour 
samples of different Hues, but equal Value and Chroma. Observers picked up a sample from the circle looking as similar as the one in the reference box, then another sample looking as similar as the sample in the test box. The research assistant noted colour codes and returned the small samples back to the circle.

Then the observers were asked to evaluate if and in the case, how much the Value and the Chroma in the test box is different from the Value and Chroma in the reference box. An adequate page from the Munsell book of colour (a page with the Hue as in the reference box) was used as a reference, see Figure 6 (Munsell, 2015). Again, the assistant noticed the results.

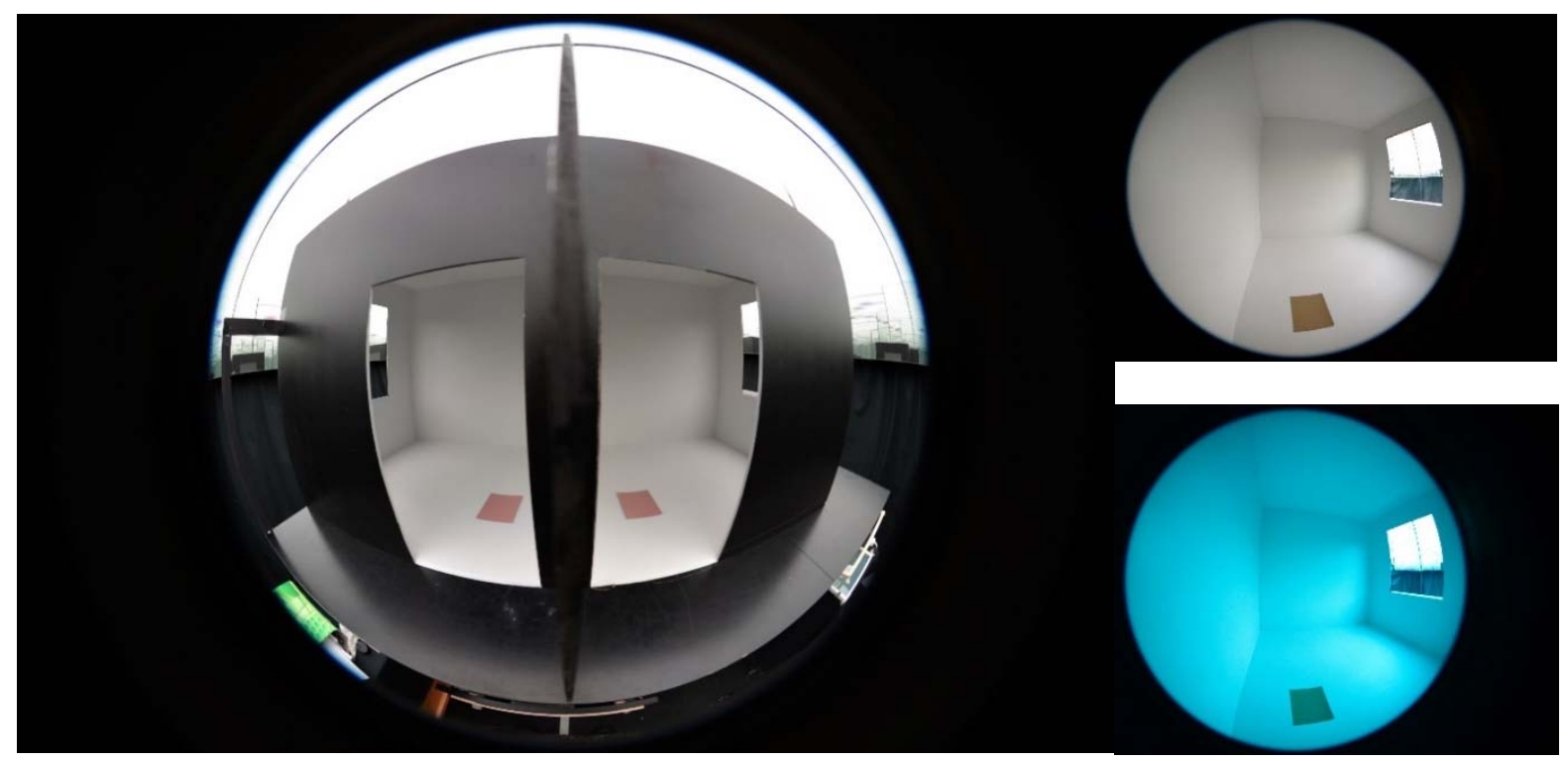

Figure 4 - Two boxes in the artificial sky; the reference to the left and the test box to the right.

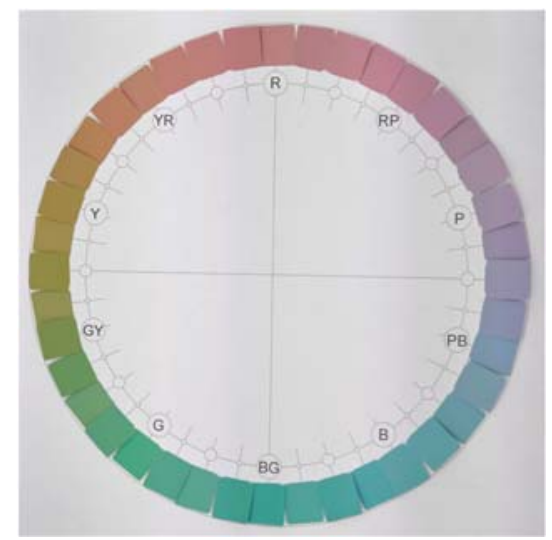

Figure 5 - A section through the Munsell system used in the experiment. Different Hues, equal Value and Chroma 


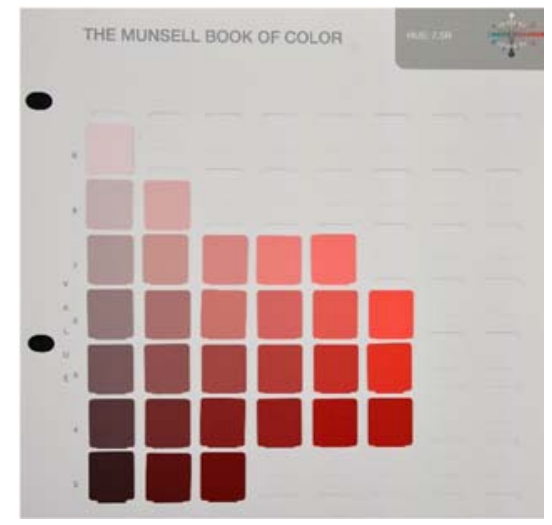

Figure 6 - Photo of a page from the Munsell book of color.

Equal Hue, different Value and Chroma.

The spectral transmittance was measured for the following glass types:

ET electrotropic in two states: -on and -off,

EC electrochromic in three states: coloured, midpoint and uncoloured

PC photochromic see Figure 7.

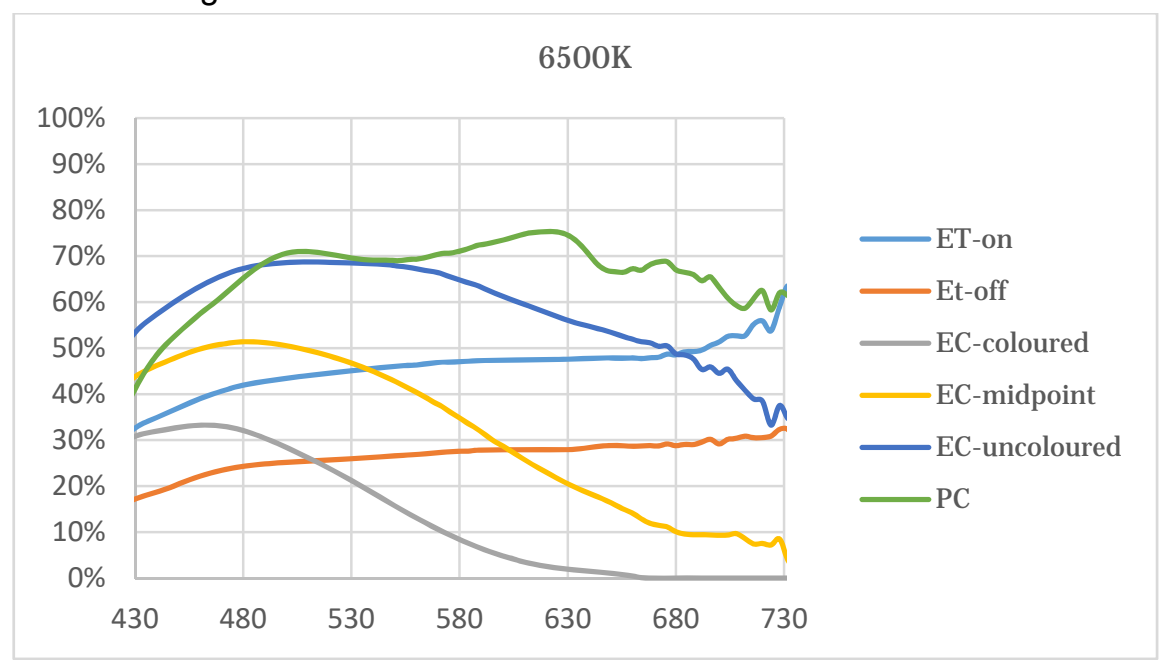

Figure 7 - Spectral Power Distribution of glass.

\section{Results}

\subsection{Value}

In the Munsell colour system the Value is measured on the scale from 0 (black) to 10 (white). For the purpose of this study we have changed the scale to $0.0-1.0$ (white). The reduction of Value due to glazing as perceived by observers is shown in the Table 2 in yellow. The number represents average value for eight samples as perceived by three expert-observers. The average spectral transmittance $T_{a}$ and the median spectral transmittance $T_{m}$ are also shown, together with the Expected reduction in Value (1- $\mathrm{T}_{\mathrm{a}}$ and $1-\mathrm{T}_{\mathrm{m}}$ respectively).

It is rather clear that the EC-coloured glazing has lowest transmittance of all glazing types. Consequently, the reduction of Value should be the highest. The observers reported the highest reduction exactly for this glass, namely 0.94 . Quite good agreement (up to 0.1 on the scale 0.0 -1.0) between expected reduction and the perceived reduction can be observed for all glazing types, the lowest for ET-off.

According to the present results, the expected $\mathrm{T}_{\mathrm{m}}$ reduction seems to be the best measure of perceived reduction of Value. 
Table 2 - Perceived Reduction of Value versus measured ones.

\begin{tabular}{|l|l|l|l|l|l|l|}
\cline { 2 - 7 } \multicolumn{1}{l|}{} & $\begin{array}{l}\text { ET- } \\
\text { on }\end{array}$ & $\begin{array}{l}\text { ET- } \\
\text { off }\end{array}$ & $\begin{array}{l}\text { EC } \\
\text { coloured- }\end{array}$ & $\begin{array}{l}\text { EC } \\
\text { midpoint- }\end{array}$ & $\begin{array}{l}\text { EC } \\
\text { uncoloured- }\end{array}$ & PC \\
\hline Average Transmittance Ta & 0.46 & 0.27 & 0.13 & 0.32 & 0.59 & 0.67 \\
Expected reduction & 0.54 & 0.73 & 0.87 & 0.68 & 0.41 & 0.33 \\
\hline Median Transmittance Tm & 0.46 & 0.27 & 0.08 & 0.29 & 0.59 & 0.68 \\
Expected reduction & $\mathbf{0 . 5 4}$ & $\mathbf{0 . 7 3}$ & $\mathbf{0 . 9 5}$ & $\mathbf{0 . 7 1}$ & $\mathbf{0 . 4 1}$ & $\mathbf{0 . 3 2}$ \\
\hline $\begin{array}{l}\text { The perceived reduction of } \\
\text { Value, average for all 8 samples }\end{array}$ & $\mathbf{0 . 4 4}$ & $\mathbf{0 . 5 7}$ & $\mathbf{0 . 9 4}$ & $\mathbf{0 . 7 9}$ & $\mathbf{0 . 3 4}$ & $\mathbf{0 . 3 5}$ \\
\hline
\end{tabular}

\subsection{Chroma}

Following the Lynes argumentation regarding the gamut area, we have looked at the gamut area for the glazing, see Figure 8 and the Table 3 . In our study, the gamut area is the area of the octagon defined by the $8 \mathrm{CIE}$ test colours (red colour on figure 8 ).

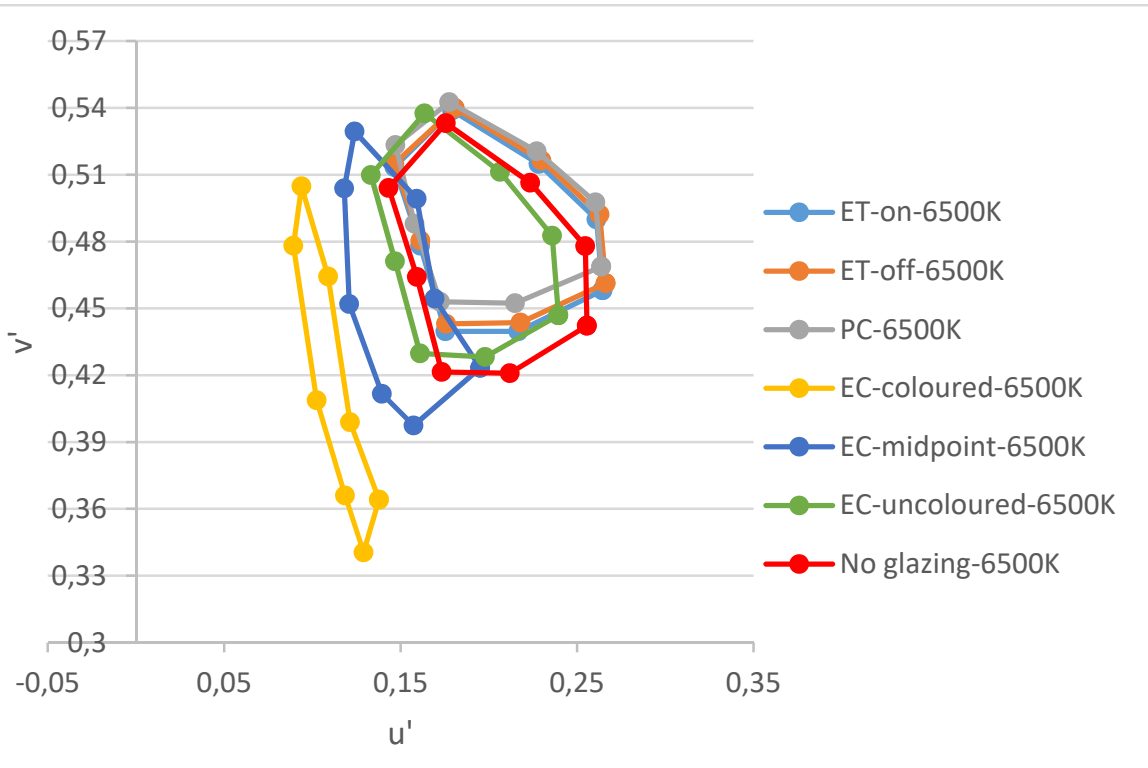

Figure 8 - Gamut area for the respective glass types at the $u^{\prime}$ - v' diagram

Table - 3 Gamut area for all types of glazing based on u' v' values

\begin{tabular}{|c|c|c|c|c|c|c|c}
\hline & open & ET-on & ET-off & $\begin{array}{l}\text { EC- } \\
\text { coloured }\end{array}$ & $\begin{array}{l}\text { EC- } \\
\text { midpoint }\end{array}$ & $\begin{array}{l}\text { EC- } \\
\text { uncoloured }\end{array}$ & PC \\
\hline Gamut area & 0.0084 & 0.0077 & 0.0077 & 0.0023 & 0.0052 & 0.0076 & 0.0071 \\
\hline Gamut area (\%) & $100 \%$ & $92 \%$ & $92 \%$ & $27 \%$ & $62 \%$ & $90 \%$ & $85 \%$ \\
\hline $\begin{array}{c}\text { Gamut area 0.0 } \\
-1.0\end{array}$ & 1 & 0.92 & 0.92 & 0.27 & 0.62 & 0.9 & 0.85 \\
\hline $\begin{array}{c}\text { Calculated } \\
\text { average Chroma }\end{array}$ & & 0.96 & 0.96 & 0.52 & 0.79 & 0.95 & 0.92 \\
\hline $\begin{array}{c}\text { Calculated av. } \\
\text { reduction }\end{array}$ & & $\mathbf{0 . 0 4}$ & $\mathbf{0 . 0 4}$ & $\mathbf{0 , 4 8}$ & $\mathbf{0 . 2 1}$ & $\mathbf{0 . 0 5}$ & $\mathbf{0 . 0 8}$ \\
\hline $\begin{array}{c}\text { Perceived } \\
\text { average } \\
\text { reduction of the } \\
\text { Chroma }\end{array}$ & $\mathbf{0 . 0 3}$ & $\mathbf{0 . 0 3}$ & $\mathbf{0 . 1 6}$ & $\mathbf{0 . 1 0}$ & $\mathbf{0 . 2}$ (red) & $\mathbf{0 . 0 5}$ \\
\hline
\end{tabular}


As expected, the gamut area is largest for no glazing. The glazings ET-on, ET-off and ECuncoloured has a bit smaller gamut area, $(90-92 \%$ of the no-glass) the PC has $85 \%$ and ECmidpoint / coloured the smallest ones 62 and $27 \%$, respectively.

The gamut area in the Munsell colour system can be calculated as a sum of triangles from the formula:

$$
A_{\mathbf{\Lambda}}=1 / 2 M N \sin (\alpha)
$$

where:
$A_{\Delta} \quad$ is the area of the triangle
$M, N$ are chromaticity numbers of two neighbouring colours
$\alpha \quad$ is the angle between them

Assuming that the Chromaticity reduction is similar for all colour samples, the reduction of the area of each triangle depends on the reduction of $\mathrm{M}$ and $\mathrm{N}$. Assuming that the same factor $k$ $(0<\mathrm{k}<1)$ can be applied to both $\mathrm{M}$ and $\mathrm{N}$, the area of a reduced triangle $A_{\mathbf{\Delta} g /}$ is:

$$
\begin{aligned}
& A_{\mathbf{\Delta} g l}=1 / 2(k M)(k N) \sin (\alpha) \\
& A_{\mathbf{\Delta} g l}=k^{2} A_{\mathbf{\Delta}} \\
& k=\left(A_{\mathbf{\Delta} g l} / A_{\mathbf{\Delta}}\right)^{0.5}
\end{aligned}
$$

Since the gamut area is a sum of triangles:

$$
k=\left(A_{g}\right)^{0.5}
$$

where

$A_{g} \quad$ is gamut area for glazing expressed as a factor of gamut area of no-glazing

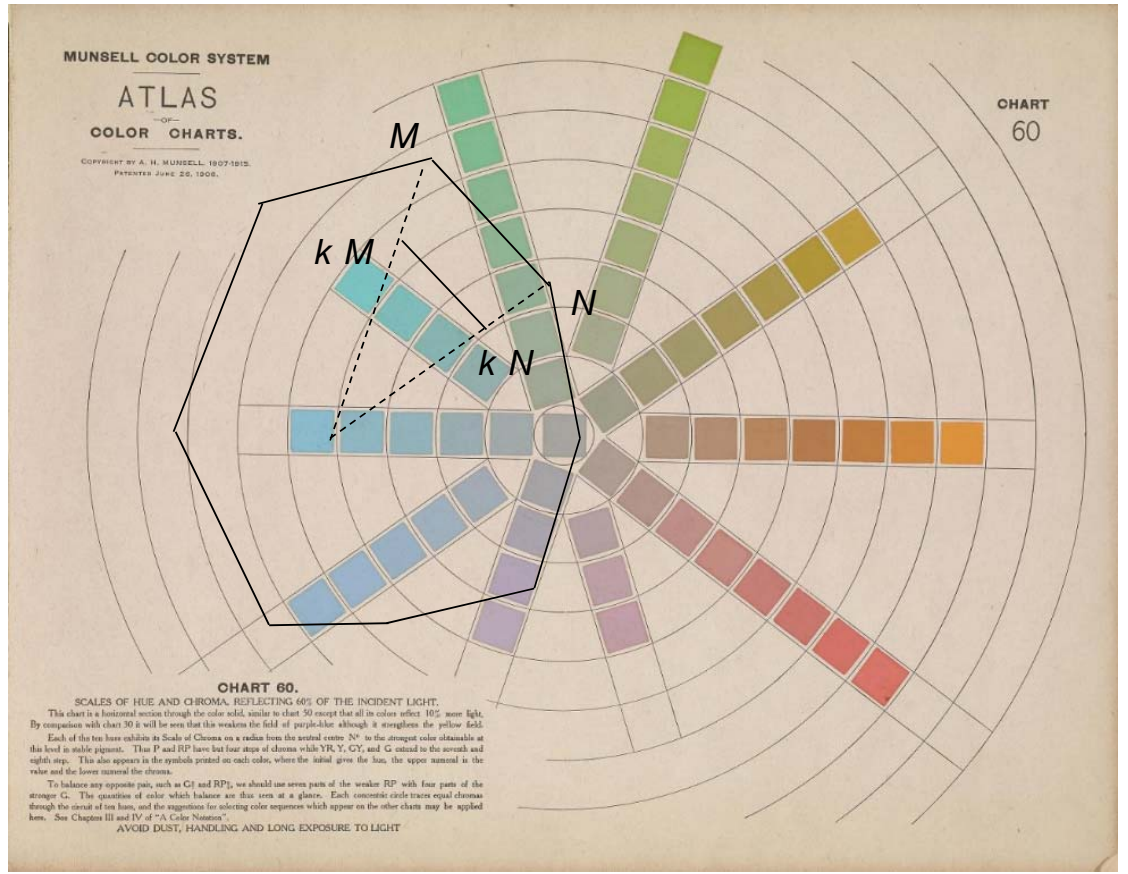

Figure 9 - Change in Chroma shown on the original page of the Munsell Color Book 
Formula 5 gives the possibility for estimation of the reduction of Chroma based on the square root of the gamut area for glazing expressed as a factor of gamut area of no-glazing. The results of calculated and perceived differences in Chroma for ET-on, ET-off and PC are very similar, Table 3, but in the case of EC the differences are too large. One reason is that, contrary to the assumptions, Chroma shifts differently for different samples. The samples: blue, green and violet changed little, while the red - yellow samples show the change $0,2-0,4$ which coincides with the calculated values.

\subsection{Hue}

The Hue Conservation Index proposed by Lynes is problematic for EC glass, since both, the Transmittance at trough $\mathrm{Td}$ and the Transmittance at $700 \mathrm{~nm} \mathrm{~Tb}$, Equation 1, are zero, the Transmittance at peak Tc is larger than the Transmittance at $525 \mathrm{~nm} \mathrm{Ta}$, consequently the $\mathrm{HCl}$ will be larger than 1.0, opposite to the Lynes intension of $\mathrm{HCl}$ being between 0.0 and 1.0.

The precise prediction of the Hue change is probably the most challenging task since the hue shift on the CIE u'v' graph can be measured as a distance between respective points, the results are shown in the table 3, while the Hue shift in the Munsell colour system are measured in angles, figure 2 and 11.

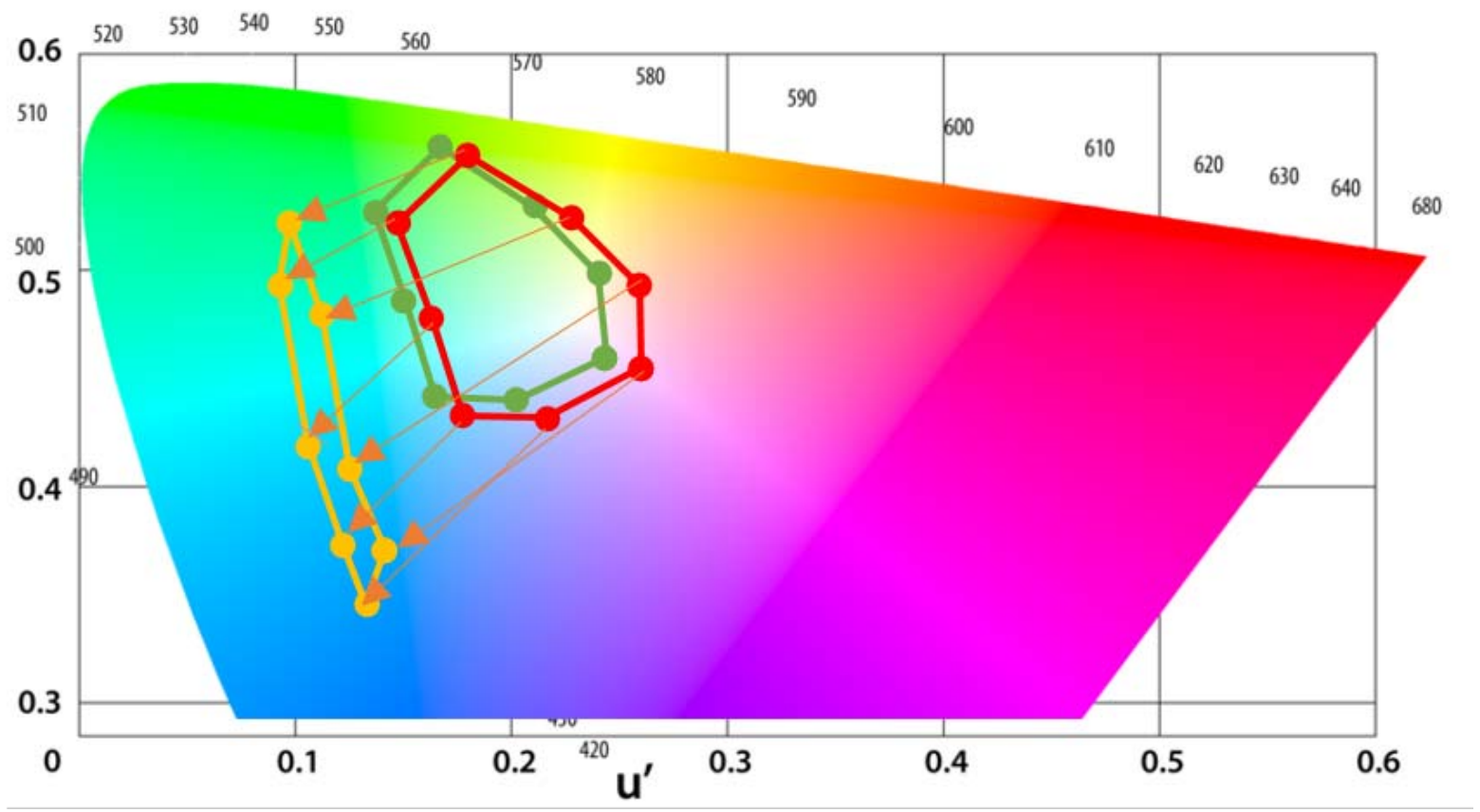

Figure 10 - Hue shift as a distance at the u'v' diagram. 


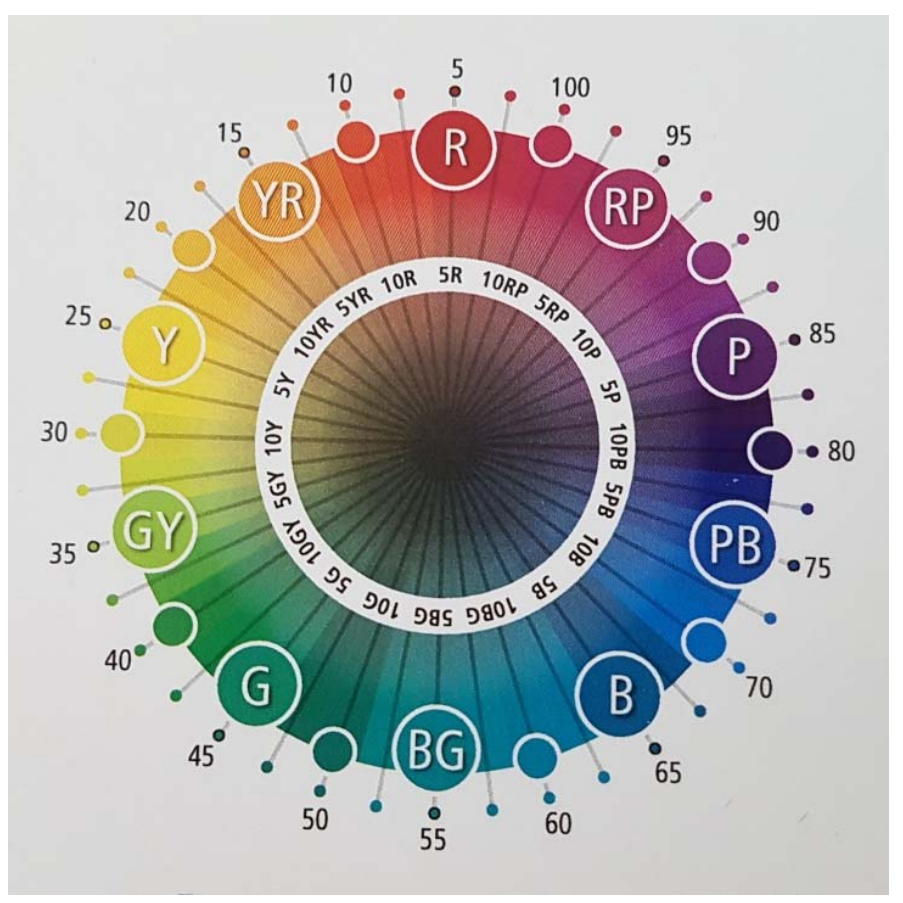

Figure 11 - Munsel Hue Designations, collected from the Munsell Book of Color

Considering Munsell points the largest average Hue shift was registered for the EC-coloured, over 11 points, that means a bit larger shift than from red R to red-purple RP. For EC-midpoint the shift is half as large. The smallest shift 1.3 was registered for ET-on. ET-off and PC glazings, both caused about 2 points shift of Hue.

The distance on the u'v' diagram gives quite similar results. For comparison the average shift distance have been multiplied by 100 . According to the results the average shift distance at the u'v' diagram multiplied by 100 gives a good prediction of Hue shift in the Munsell colour system.

Table 4 - The distance for each colour sample point at the u'v' graph compared to no glazing

\begin{tabular}{|l|c|l|l|l|l|l|}
\hline & ET-on & ET-off & $\begin{array}{l}\text { EC } \\
\text { coloured- }\end{array}$ & $\begin{array}{l}\text { EC } \\
\text { midpoint- }\end{array}$ & $\begin{array}{l}\text { EC } \\
\text { uncoloured- }\end{array}$ & PC \\
\hline Sample 1 & 0.01 & 0.02 & 0.15 & 0.09 & 0.02 & 0.02 \\
\hline Sample 2 & 0.01 & 0.01 & 0.12 & 0.06 & 0.02 & 0.01 \\
\hline Sample 3 & 0.01 & 0.01 & 0.09 & 0.05 & 0.01 & 0.01 \\
\hline Sample4 & 0.01 & 0.01 & 0.06 & 0.03 & 0.01 & 0.02 \\
\hline Sample 5 & 0.01 & 0.02 & 0.08 & 0.04 & 0.01 & 0.02 \\
\hline Sample 6 & 0.02 & 0.02 & 0.08 & 0.04 & 0.01 & 0.03 \\
\hline Sample 7 & 0.02 & 0.02 & 0.12 & 0.06 & 0.02 & 0.03 \\
\hline Sample 8 & 0.02 & 0.02 & 0.14 & 0.06 & 0.02 & 0.03 \\
\hline Average shift distance & $\mathbf{0 . 0 1}$ & $\mathbf{0 . 0 2}$ & $\mathbf{0 . 1 0}$ & $\mathbf{0 . 0 5}$ & $\mathbf{0 . 0 2}$ & $\mathbf{0 . 0 2}$ \\
\hline Average shift distance*100 & $\mathbf{1 . 0}$ & $\mathbf{2 . 0}$ & $\mathbf{1 0 . 0}$ & $\mathbf{5 . 0}$ & $\mathbf{2 . 0}$ & $\mathbf{2 . 0}$ \\
\hline $\begin{array}{l}\text { Perceived average Hue shift } \\
\text { in Munsell points }\end{array}$ & $\mathbf{1 . 3}$ & $\mathbf{2 . 0}$ & $\mathbf{1 1 . 2}$ & $\mathbf{5 . 6}$ & - & $\mathbf{2 . 0}$ \\
\hline
\end{tabular}




\section{Conclusions}

The study shows that the visual perception of colour change due to a window glass may be to a certain degree predicted by measurements of spectral transmittance of the glass.

Value: the expected value shift, that is one minus median spectral transmittance, is a good measure of perceived shift of Value.

Chroma: the shift in Chroma may be predicted to a certain degree using formula 5, that is, the square root of the gamut area for glazing expressed as a factor of gamut area of no-glazing

Hue: the average shift distance at the u'v' diagram, multiplied by 100 , gives a good prediction of average Hue shift in the Munsell colour system points.

\section{References}

ARBAB S, et al. 2017. The impact of advanced glazing on colour perception. Journal of the Internationa Colour Association (JAIC). 2017:50-68.

ARBAB S. MATUSIAK B.S. 2018. Toward colour rendering method of window glass, Colour research and application. DOI: 10.1002/col.22247

LYNES J. 2015; Colour of Daylight Indoors. http://www.cibse.org/networks/groups/daylight/daylight-past-presentations.

MATUSIAK B.S., 2014. Overcast sky simulator in the Daylight laboratory at NTNU, Trondheim. Lumen V4; Visegrád, Hungary.

MUNSELL Color 2015. The Munsell Book of Color Grand Rapids, Michigan 49512 USA 877.888.1720, munsell.com.

YAGUCHI H, et al. 2017 Colour fidelity index for accurate scientific use. CIE 2017 